\title{
Serosurvey of hepatitis A virus and E virus infection among municipal sweepers working in the largest city in the south of Iran
}

\section{Jamal Sarvari ( $\nabla$ sarvarij@sums.ac.ir)}

Shiraz Medical School: Shiraz University of Medical Sciences

\section{Seyed Younes Hosseini}

Shiraz Medical School: Shiraz University of Medical Sciences

\section{Negar Joharinia}

Shiraz Medical School: Shiraz University of Medical Sciences

Seyed Ali Hosseini

Shiraz Medical School: Shiraz University of Medical Sciences

\section{Saeed Firoozi Ghahestani}

Shiraz Medical School: Shiraz University of Medical Sciences

\section{Rozita Ghojoghi}

Shiraz Medical School: Shiraz University of Medical Sciences

\section{Kourosh Dorost}

Shiraz Medical School: Shiraz University of Medical Sciences

\section{Mohsen Moghadami}

Namazi Hospital

Abolfazl Gheshlaghi

Shiraz Medical School: Shiraz University of Medical Sciences

Omid Jaberi

Shiraz Medical School: Shiraz University of Medical Sciences

Rohollah Khoshbakht

Occupational Health Center

\section{Research Article}

Keywords: Hepatitis E virus, Hepatitis A virus, Street sweeper, Serology, Iran

Posted Date: July 16th, 2021

DOI: https://doi.org/10.21203/rs.3.rs-714305/v1 
License: (c) (i) This work is licensed under a Creative Commons Attribution 4.0 International License. Read Full License 


\section{Abstract \\ Background}

Given the importance of Hepatitis A (HAV) and Hepatitis E (HEV) infection in careers like street sweeping, this study was conducted to determine the exposure rate in urban solid waste collectors/sweepers in the south of Iran.

\section{Materials and methods}

In this cross-sectional study, the sera samples of 385 waste collectors/sweepers from all districts of Shiraz, southern Iran, were collected. A questionnaire was used to gather data on their demographic and occupational characteristics, as well as their awareness of viral hepatitis disease. The rate of HAV and HEV sero-prevalence was determined by commercial ELISA kits.

\section{Results}

All partisans were male with a mean age of $41 \pm 8$ years. ELISA assay showed that all of participants were positive for anti-HAV Ab. Moreover, 62out of 385 (16.1\%) subjects were positive for anti-HEV IgG Ab. Also, statistical analysis showed that the frequency of $\operatorname{lgG} \mathrm{Ab}$ against HEV among the age group of 20$30,31-40,41-50$ and over 50 years old was $4.5 \%, 10.1 \%, 17.4 \%$, and $36.7 \%$ that was statistically significant $(P<0.001)$. Based on the work experience, current and previous jobs, residency, personal hygiene and knowledge status of hepatitis disease and transmission, the results showed that there was no statistically significant difference between anti-HEV positive and negative sweepers ( $p \otimes 0.05)$.

\section{Conclusion}

Our results indicated that the frequency of anti-HAV and HEV IgG among sweepers is slightly higher than the normal population; it does not seem that garbage collecting/sweeping career could be a significant risk factor for HAV and HEV infection.

\section{Background}

Hepatitis A (HAV) and Hepatitis E (HEV) infections are still worldwide concerns of acute hepatitis. They are often transmitted focally and orally and cause self-limiting hepatic infections with no sequels(1). The global disparity in HAV and HEV prevalence depends on the degree of hygiene and health, plus factors such as socioeconomic status(2).

HAV is mainly transmitted through contaminated food or water or by spreading from person to person (3). In addition to enhancing sanitation and injecting HAV vaccine, the prevalence of viruses in the 
developed society follows a downward trend, but the infection rate tends to rise $(4,5)$. However, there is evidence that in developing countries the number of people infected with HAV has remain high (2). In one study, the anti-HAV Ab was found in $99.2 \%$ of the people $>30$ years old in Fars, Iran (6). Moreover, a study from Shiraz indicated that the rate of seroprevalence was $68 \%$ among 15 -year-old subjects (7). The prevalence of HAV infection is mainly affected by general hygiene, especially with regard to toilet facilities, water supplies, and food preparation methods, indicating living standards and socioeconomic status (8). Many studies have indicated that some jobs are at higher risk of HAV and HEV infections due to the path of transmission. Some workers such as military personnel, social workers and health workers are more at risk of being infected with these viruses due to frequent contaminants, water, and sewage. In particular, sweepers could be more at risk of infection of HAV since they are in daily contact with contamination (9).

HEV is spread through 2 different patterns including contaminated water and eating undercooked meat with a zoonosis cycle $(10,11)$. The main route of HEV infection is consumption of contaminated water. HEV has a different serological worldwide pattern which reaches $15-20 \%$ in the developing countries, but it is still about $5 \%$ in the developed countries $(12,13)$. Iran, as one of the Middle East countries, is an endemic area for HEV infections, despite the frequent reports of various seroprevalence rates in different provinces. The previous studies have reported that the prevalence of $\mathrm{HEV}$ is about $10 \%$ with a maximum and minimum of $46 \%$ and $1 \%$, respectively $(14,15)$. A recent study shows that HEV infections are still endemic herein(16). Raw sewage and water supplies contain HEV isolates; therefore, street sweepers could be at risk of HEV infection(17). So far, however, few studies have shown a prevalence of 45 percent HEV infection in street sweepers, no research has revealed the prevalence of HEV infection among Iranian street sweepers in highly congested areas (18). Therefore, the present study aimed to determine the seroprevalence of HAV and HEV in waste collectors of Shiraz, southern Iran.

\section{Methods}

\section{Patients and blood sampling}

This is a cross-sectional study on waste collectors in Shiraz, the biggest city in the south of Iran. A total of 385 sweepers from all 10 districts of Shiraz city were randomly enrolled. They have consented to participate in study before filing the questionnaire file. Their blood samples were collected and sera were isolated. All sampling stages were performed on participants who signed the written consent forms. The study was approved based on the ethical standards of the Shiraz University of Medical Sciences, with the code number of IR.SUMS.MED.REC.1389.259. Five $\mathrm{mL}$ blood sample was collected from each patient. The sera were separated from the whole blood by centrifugation at 3000 RPM, and the separated sera were stored at $-20^{\circ} \mathrm{C}$ until use. The questionnaire contained questions on demographic characteristics, sanitation status at work, wearing mask and/or gloves, hand washing, and other factors.

\section{Elisa Test For Detection Of Virus Exposure}


In order to investigate the exposure rate of the participants to HAV and HEV viruses, we evaluated the total antibody against them by commercial Enzyme linked Immunosorbent assay kits (Dia.Pro. Milano, Italy), according to the manufacturer's instructions. Index values for seropositivity in each test were calculated based on the instructions of the kits.

\section{Statistical Analysis}

Statistical analysis was performed using SPSS (version 16.0; SPSS Inc., Chicago, IL, USA). In addition to the descriptive test, crosstab test and Chi-square test were used to compare different variables and find out the association of two-way tables. A p-value less than 0.05 was considered significant.

\section{Results}

All 385 street sweepers were men with a mean age of $40.98 \pm 8.437$ years old (Table 1$)$. Surprisingly, all individuals who were positive for IgG Ab against HAV indicated evidence of past infection with HAV. Therefore, no more statistical analysis regarding the HAV and regarding demography and sanitation status at work was performed. 
Table 1

Demographic, occupational characteristics and awareness about viral hepatitis disease status of the recruited subjects and relative seropositivity to HEV among municipal sweepers working in the largest city in the south of Iran

\begin{tabular}{|c|c|c|c|c|c|c|c|}
\hline \multirow[t]{2}{*}{ Characteristic } & \multicolumn{2}{|c|}{ Frequency } & \multicolumn{2}{|c|}{ Negative subjects } & \multicolumn{2}{|c|}{ Positive subjects } & \multirow[t]{2}{*}{ P-value } \\
\hline & No. & $\%$ & No. & $\%$ & No. & $\%$ & \\
\hline Subjects & 385 & 100 & 323 & 83.9 & 62 & 16.1 & \\
\hline Age group (years) & & & & & & & $<0.001$ \\
\hline $20-30$ & 44 & 11.5 & 42 & 95.5 & 2 & 4.5 & \\
\hline $31-40$ & 148 & 38.5 & 133 & 89.9 & 15 & 10.1 & \\
\hline $41-50$ & 132 & 34.4 & 109 & 82.6 & 23 & 17.4 & \\
\hline $50<$ & 60 & 15.6 & 38 & 63.3 & 22 & 36.37 & \\
\hline Service in Years & & & & & & & 0.490 \\
\hline$\geq 5$ & 307 & 79.95 & 255 & 83.1 & 52 & 16.9 & \\
\hline 5> & 77 & 20.05 & 67 & 87 & 10 & 13 & \\
\hline Previous job & & & & & & & 0.629 \\
\hline$\geq 5$ & 307 & 81 & 259 & 83.3 & 52 & 16.7 & \\
\hline Related & 51 & 13.4 & 45 & 88.2 & 6 & 11.8 & \\
\hline Unrelated & 21 & 5.6 & 17 & 81 & 4) & 19 & \\
\hline living place & & & & & & & 1.000 \\
\hline Urban & 336 & 90.6 & 281 & 83.6 & 55 & 16.4 & \\
\hline Rural & 35( & 9.4 & 30 & 85.7 & 5 & 14.3 & \\
\hline $\begin{array}{l}\text { Frequency of washing } \\
\text { hands and face }\end{array}$ & & & & & & & 0.772 \\
\hline$\geq 2$ & 288 & 92.9 & 240 & 83.3 & 48 & 16.7 & \\
\hline $2>$ & 22 & 7.9 & 18 & 81.8 & 4 & 18.2 & \\
\hline $\begin{array}{l}\text { Manner of washing } \\
\text { hands and face }\end{array}$ & & & & & & & 1.000 \\
\hline Only water & 19 & 5.6 & 16 & 84.2 & 3 & 15.8 & \\
\hline Soap + Water & 321 & 94.4 & 266 & 82.9 & 55 & 17.1 & \\
\hline Mask usage & & & & & & & 0.283 \\
\hline
\end{tabular}




\begin{tabular}{|c|c|c|c|c|c|c|c|}
\hline \multirow[t]{2}{*}{ Characteristic } & \multicolumn{2}{|c|}{ Frequency } & \multicolumn{2}{|c|}{ Negative subjects } & \multicolumn{2}{|c|}{ Positive subjects } & \multirow[t]{2}{*}{ P-value } \\
\hline & No. & $\%$ & No. & $\%$ & No. & $\%$ & \\
\hline Always & 276 & 71.9 & 235 & 85.1 & 41 & 14.9 & \\
\hline Sometimes & 108 & 28.1 & 87 & 80.6 & 21 & 19.4 & \\
\hline
\end{tabular}

Moreover, the results indicated that $16.1 \%(62 / 385)$ of street sweepers were positive for IgG Ab against HEV. The mean age of street sweepers that were positive and negative for IgG Ab against HEV were 46.31

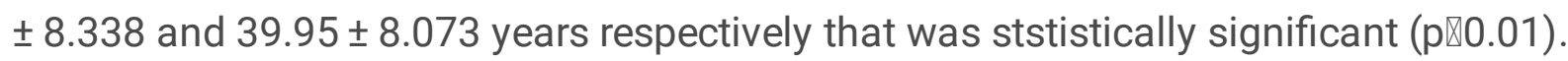

Also, statistical analysis showed that the frequency of $\lg \mathrm{G}$ Ab against HEV among the age group of 20$30,31-40,41-50$ and over 50 years old were $4.5 \%, 10.1 \%, 17.4 \%$, and $36.7 \%$ that was statistically significant $(P<0.001)$, with an increasing trend. Based on the sweeper's work experience, the results among anti-HEV seropositive individuals indicated that $16.9 \%$ (52/307) of street sweepers had five or more than five years, and $13 \%(10 / 77)$ had less than five years of work experience in all professions, and the difference was not significant $(p>0.05)$. According to the relationship between the sweepers' current and previous jobs, $16.7 \%$ (52/307) of anti-HEV seropositive street sweepers had been working for more than five years as a sweeper; $11.8 \%(6 / 51)$ of them had previous work experience the same as the current job, and 19\% (4/21) had unrelated previous work experience. As to the sweeper's living place, $16.4 \%$ $(55 / 336)$ of the anti-HEV seropositive street sweepers lived in urban areas and $14.3 \%(5 / 35)$ in rural areas.

One of the parameters considered in this study was anti-HEV seropositive individuals' personal hygiene. The results revealed that $16.7 \%(48 / 288)$ of them washed their face and hands twice or more, and $18.2 \%$ $(4 / 22)$ did so fewer than twice, and the difference was not statistically significant $(p=0.78)$. Besides, $15.8 \%(3 / 19)$ of street sweepers who washed their face and hands only with tap water and $17.1 \%$ $(55 / 321)$ of those who used water plus soap were anti-HEV seropositive. Another parameter was mask usage during sweeping and anti-HEV seropositivity. $19.4 \%$ (21/108) rarely used masks, and $14.9 \%$ $(41 / 276)$ always used masks; however, it was not statistically significant $(p=0.2)$. Based on municipal district division, the anti-HEV seroprevalence between street sweepers was $10(27.8 \%)$ for district 1 , $7(24.1 \%)$ for district $2,8(18.6 \%)$ for district $3,4(8.9 \%)$ for district $4,6(15.4 \%)$ for district $5,4(13.3 \%)$ for district $6,7(15.9 \%)$ for district 7, 4 (9.8\%) for district $8,6(12.8 \%)$ for district 9, and 6 (19.4\%) for district 10. The highest prevalence of anti-HEV IgG was detected in municipal street sweepers in districts 1 (27.8\%) and $2(24.1 \%)$, and the lowest prevalence was discovered in districts 4 (8.9\%) and $8(9.8 \%)$.

In addition, another point addressed in this study was the status of knowledge about hepatitis disease and transmission. The analysis of the questionnaire showed that out of all sweepers in terms of transmission routes of hepatitis viruses 15\% (9/60) from HEV seropositive and 13.3\% (42/316) from HEV seronegative group were aware of the correlation between needle sticking, drug abusing, and tattooing and hepatitis transmission. Also, 13.3\% (8/60) seropositive and $11.7 \%(37 / 316)$ seronegative group knew about blood transfusion and hepatitis viruses infection, $6.7 \%$ (4/60) from seropositive, and $8.2 \%(26 / 316)$ 
from seronegative group knew about hepatitis vaccination. None of the seropositive street sweepers had information about possible available treatment for hepatitis diseases, whereas it was $0.6 \%(2 / 316)$ for seronegative ones.

\section{Discussion}

Given the importance of hepatitis in international communities, understanding the exposure rate in some careers would not only contribute to global prevention, but also highlight their importance as possible risk factors. In the current study, for the first time, the seroprevalence of hepatitis $E$ and $A$ viruses was investigated among Shiraz municipal district street sweepers, the largest city in the south of Iran.

Previous studies reported that the seroprevalence of HAV among adults (around 30 years old) in Iran and Fars province was over $82.6 \%$ (19) and 99\% (6), respectively, which was much similar to our study that revealed a $100 \%$ rate among street sweepers.

As the second step, this study showed that $16.1 \%$ of the investigated cases were posetive for anti-HEV $A b$. The primary idea has suspected a higher rate, more significant than the normal population, due to common route of transmission (fecal-oral) and exposure of this particular group to sewage, contaminated water, and poor occupational hygiene, especially when eating and drinking at work. A study carried out by Asaei et al. in Shiraz reported the sero-prevalence of $13.4 \%$ for total anti-HEV among the healthy population (20). Recently, it has been reported that $10.4 \%(26 / 151)$ of HIV infected patients in Fars Province were positive for anti-HEV Ab(20).

Sweeping and collecting garbage are among the careers in which the spread of oral-fecal infection is more common. A recent study in India indicated a higher concentration of fecal pollution, as marked by E.coli detection, at the end of the daily work activities (21). Another study on sweepers has indicated that they are at high risk of infection with Toxocara infection. Therefore, oral-fecal contamination by several microorganisms circulating among humans in this way is common in the mentioned group (22). In Egypt, parasitic infestations including Entameba histolytica and Hymenolepis nana were also detected more significantly in stool analysis street sweepers than university employees (23). The findings of Kretchy et al. revealed that solid waste collectors should be provided with proper protective measures and sanitation facilities, and they should be trained on hygienic behaviors to prevent oral-fecal contamination by food/water-borne contaminants (24) .

In the case of HEV, few studies have been evaluated to determine its sero-prevalence among street sweepers or waste collectors. In 2003 , Vadiya et al. showed that $56.5 \%$ of sewage workers were anti-HEV IgG positive; this is significantly higher exposure rate than the relevant normal population. Therefore, a career with direct contact with sewage or sewage-contaminated materials can be considered a risk factor (25). In addition, a study by Farshadpour et al. has shown a significant difference between the prevalence of HEV antibodies and the living place (26). Meanwhile, the study of Saffar et al. in 2009 revealed that the most significant relationship between seroprevalence of this virus and living place was in rural areas (27). 
In our study, $16.4 \%$ of street sweepers lived in rural areas, and $14.3 \%$ of those who lived in rural areas were HEV seropositive. However, no significant association was found.

In a noble finding, the study revealed that $6.7 \%$ of seropositive and $8.2 \%$ of seronegative individuals were aware of hepatitis vaccination although no significant association was reported. On the other hand, $0.6 \%$ of seronegative and none of the seropositive street sweepers were aware of the treatment of hepatitis with no statistically significant association (20). Vaidya and Asaei's studies revealed that the seroprevalence of anti-HEV IgG is directly related to age in sewage collectors, which is in accordance with our results. The seroprevalence of anti-HEV IgG in street sweepers was $4.5 \%$ in the age range of 20 to 30 years, $10.1 \%$ in 31 to 40 years, $17.4 \%$ in 41 to 50 years, and $36.7 \%$ in sweepers over 50 years, which indicates a significant relationship between aging and increase in anti-HEV seropositivity among the sweepers $(12,24)$.

Also, in Vaidya's study, a significant increase of anti-HEV IgG was reported in those in contact with urban garbage for more than 5 years $(67.6 \%)$ compared to those who had worked for less than 5 years $(38.9 \%)$ (25). In the present study, the anti-HEV IgG seroprevalence was $16.9 \%$ among people with 5 or over 5 years of working, while this figure was $13 \%$ in people with less working duration; however, no statistically significant relationship was observed between the HEV seroprevalence and the working duration.

Although sanitation such as hand washing has been recommended in most articles as an effective way for public health $(28,29)$, we did not find a relationship between the seroprevalence of HEV and hand washing. The present study also confirmed that $17.1 \%$ of street sweepers who washed their hands with soap and water and $15.8 \%$ of those who used only water to wash their hands and faces were positive for anti-HEV IgG. However, it is clearly indicated that sanitation status makes this population more vulnerable to infection by food/waterborne microorganisms, as demonstrated previously(24).

Also, $16.7 \%$ of street sweepers who washed their hands and face more than 2 times during and after work and $18.3 \%$ of those who did so fewer than 2 times were positive, respectively. However, no significant relationship was found between the sero-prevalence of anti-HEV and the number and method of washing hands and faces. On the other hand, Dahiya et al. pointed out the importance of using mask to prevent HEV infection which is transmitted through the mouth (30). In the present study, $14.9 \%$ of street sweepers who always used mask during sweeping and $19.4 \%$ of those who rarely did so were HEV seropositive. However, no significant difference was found between the seroprevalence of anti-HEV and wearing face mask.

Tha absence of molecular assays to find the status of virus genome among the individuals and nonsweeper men in the control group was a limitation of the present study. In conclusion, although our results showed that $100 \%$ and $16.1 \%$ of street sweepers were positive for anti-HAV and HEV IgG Ab respectively, which was slightly higher than the normal population. However, it does not seem that garbage collecting/sweeping career is significant risk factors of HAV and HEV infection. 


\section{Conclusion}

Our results indicated that the frequency of anti-HAV and HEV IgG among sweepers is slightly higher than the normal population; it does not seem that garbage collecting/sweeping career could be a significant risk factor for HAV and HEV infection.

\section{Abbreviations}

HAV: Hepatitis A Virus; HEV: Hepatitis E Virus; Ab: Antibody; ELISA: Enzyme Linked Immunosorbent Assay

\section{Declarations}

\section{Ethics approval and consent to participate}

We declare that informed consent was obtained from all study subjects and the study was approved by the local ethical committee of Shiraz University of Medical Sciences (IR.SUMS.MED.REC.1389.259).

\section{Consent for publication}

Not applicable.

\section{Availability of data and material}

Data available within the article.

\section{Competing interests}

The authors declare that they have no competing interests.

\section{Funding}

The present study financially supported by the office of vice-chancellor for research of Shiraz University of Medical Sciences (no: 19266 and 17216).

\section{Authors' contributions}

Study concept: Hosseini SY, Moghadami M and sarvari J; Sample collection: Hosseini SA, , Ghojoghi R, Dorost K, Gheshlaghi A, Jaberi $\mathrm{O}$ and Khoshbakht R; Bench work: Joharinia N, Ghojoghi R; Data analysis: Joharinia N, Firoozi Ghahestani S, Jaberi $O$ and Khoshbakht R; Manuscript derafting: Joharinia N, Firoozi Ghahestani S, Ghojoghi R, Hosseini SA, Dorost K and Gheshlaghi A; Critical revision of the manuscript: Hosseini SY, Moghadami M and Sarvari J. All authors read and approved the fnal manuscript. 
The present study was extracted from the thesis written by Kourosh Dorost and Seyed Ali Hosseini.

\section{Authors' information}

${ }^{1}$ Department of Bacteriology \& Virology, School of Medicine, Shiraz University of Medical Sciences, Shiraz, Iran ${ }^{2}$ Department of Internal Medicine, Namazi Hospital, Shiraz, Iran ${ }^{3}$ Occupational Health Engineering, HSE Unit, Shiraz Waste Management Organization, Shiraz, Iran ${ }^{4}$ Gastroenterohepatology Research Center, Shiraz University of Medical Sciences, Shiraz, Iran

\section{References}

1. Cullen JM, Lemon SM. Comparative pathology of hepatitis A virus and hepatitis E virus infection. Cold Spring Harbor perspectives in medicine. 2019;9(4):a033456.

2. Franco E, Meleleo C, Serino L, Sorbara D, Zaratti L. Hepatitis A. Epidemiology and prevention in developing countries. World journal of hepatology. 2012;4(3):68.

3. Guzzetta G. Household transmission and disease transmissibility of a large HAV outbreak in Lazio, Italy, 2016-2017. Epidemics. 2019:100351.

4. Aggarwal R, Goel A. Hepatitis A: epidemiology in resource-poor countries. Curr Opin Infect Dis. 2015;28(5):488-96.

5. Vilibic-Cavlek T, Kucinar J, Ljubin-Sternak S, Kolaric B. Seroepidemiology of hepatitis a in the croatian population. Hepatitis monthly. 2011;11(12):997.

6. Taghavi SA, AsI MKH, Talebzadeh M, Eshraghian A. Seroprevalence study of hepatitis A virus in Fars province, southern Iran. Hepatitis monthly. 2011;11(4):285.

7. Alavian S-M. Iraq: a hot zone for HAV infection. Hepat Mon. 2005;5(3):53-6.

8. Atabek ME, Fýndýk D, Gulyuz A, Erkul I. Prevalence of anti-HAV and anti-HEV antibodies in Konya, Turkey. Health Policy. 2004;67(3):265-9.

9. Rachiotis G, Papagiannis D, Thanasias E, Dounias G, Hadjichristodoulou C. Hepatitis A virus infection and the waste handling industry: a seroprevalence study. Int J Environ Res Public Health. 2012;9(12):4498-503.

10. Li T-C, Chijiwa K, Sera N, Ishibashi T, Etoh Y, Shinohara Y, et al. Hepatitis E virus transmission from wild boar meat. Emerg Infect Dis. 2005;11(12):1958.

11. Hauser L, Roque-Afonso A-M, Beylouné A, Simonet M, Fischer BD, des Roziers NB, et al. Hepatitis E transmission by transfusion of Intercept blood system-treated plasma. Blood. 2014;123(5):796-7.

12. Asaei S, Ziyaeyan M, Moeini M, Jamalidoust M, Behzadi MA. Seroprevalence of hepatitis A and E virus infections among healthy population in Shiraz, Southern Iran. Jundishapur journal of microbiology. 2015;8(7).

13. Boutrouille A, Bakkali-Kassimi L, Crucière C, Pavio N. Prevalence of anti-hepatitis E virus antibodies in French blood donors. J Clin Microbiol. 2007;45(6):2009-10. 
14. Behzadifar M, Lankarani KB, Abdi S, Mirghaed MT, Beyranvand G, Keshavarzi A, et al. Seroprevalence of hepatitis $E$ virus in Iran: a systematic review and Meta-analysis. Middle East journal of digestive diseases. 2016;8(3):189.

15. Jamali R. Epidemiologic studies on viral hepatitis: a short review. Thrita. 2014;3(1).

16. Hesamizadeh K, Sharafi H, Keyvani H, Alavian SM, Shabankareh AN-T, Olyaie RS, et al. Hepatitis A virus and hepatitis $\mathrm{E}$ virus seroprevalence among blood donors in Tehran, Iran. Hepatitis monthly. 2016;16(1).

17. Khuroo M, Khuroo M, Khuroo N. Transmission of hepatitis E virus in developing countries. Viruses. 2016;8(9):253.

18. Ahmad T, Waheed Y, Tahir S, Safi SZ, Fatima K, Afzal MS, et al. Frequency of HEV contamination in sewerage waters in Pakistan. The Journal of Infection in Developing Countries. 2010;4(12):842-5.

19. Behzadi MA, Leyva-Grado VH, Namayandeh M, Ziyaeyan A, Feyznezhad R, Dorzaban H, et al. Seroprevalence of viral hepatitis A, B, C, D and E viruses in the Hormozgan province southern Iran. BMC Infect Dis. 2019;19(1):1027.

20. Shahriarirad R, Erfani A, Rastegarian M, Zeighami A, Arefkhah N, Ghorbani F, et al. Seroprevalence of anti-hepatitis $\mathrm{E}$ antibodies and antigens among HIV-infected patients in Fars Province, southern Iran. Virology Journal. 2020;17(1):1-5.

21. Jeggli S, Steiner D, Joller H, Tschopp A, Steffen R, Hotz P. Hepatitis E. Helicobacter pylori, and gastrointestinal symptoms in workers exposed to waste water. Occup Environ Med. 2004;61(7):6227.

22. Erfani A, Pouryousef A, Arefkhah N, Shahriarirad R, Rastegarian M, Zeighami A, et al. Seroprevalence of toxocariasis and its related risk factors among municipal street sweepers in Shiraz District in Fars Province, southern Iran. Clinical Epidemiology and Global Health. 2020.

23. Ewis A, Mohamed E, Rahma M, Hifnawy T, Arafa A. Occupational health-related morbidities among street sweepers and waste collectors at Beni-Suef, Egypt. Egyptian Journal of Occupational Medicine. 2013;37(1):79-94.

24. Kretchy J-P, Dzodzomenyo M, Ayi I, Dwomoh D, Agyabeng K, Konradsen F, et al. Risk of faecal pollution among waste handlers in a resource-deprived coastal peri-urban settlement in Southern Ghana. Plos one. 2020;15(10):e0239587.

25. Vaidya SR, Tilekar BN, Walimbe AM, Arankalle VA. Increased risk of hepatitis $E$ in sewage workers from India. Journal of occupational environmental medicine. 2003;45(11):1167-70.

26. Farshadpour F, Taherkhani R, Makvandi M. Prevalence of hepatitis E virus among adults in southwest of Iran. Hepatitis research and treatment. 2015;2015.

27. Saffar M, Farhadi R, Ajami A, Khalilian A, Babamahmodi F, Saffar H. Seroepidemiology of hepatitis E virus infection in 2-25-year-olds in Sari district, Islamic Republic of Iran. EMHJ-Eastern Mediterranean Health Journal, 15 (1), 136-142, 2009. 2009.

28. Freeman MC, Stocks ME, Cumming O, Jeandron A, Higgins JP, Wolf J, et al. Systematic review: hygiene and health: systematic review of handwashing practices worldwide and update of health 
effects. Tropical Med Int Health. 2014;19(8):906-16.

29. Wolf J, Johnston R, Freeman MC, Ram PK, Slaymaker T, Laurenz E, et al. Handwashing with soap after potential faecal contact: global, regional and country estimates. Int J Epidemiol. 2019;48(4):1204-18.

30. Dahiya P, Kamal R, Sharma V, Kaur S. "Hepatitis"-Prevention and management in dental practice. Journal of education and health promotion. 2015;4. 